\title{
Research on Cab Vibration Control Based on Parameter Hierarchical Interaction Model
}

\author{
Enyong Xu, ${ }^{1,2}$ Shuilong He $\mathbb{D}^{2,3}$ Weiguang Zheng $\mathbb{D}^{2,3}$ Tao Tang $\mathbb{D}^{3}{ }^{3}$ Chao $\mathrm{Li}^{2}$ \\ and Qibai Huang 1 \\ ${ }^{1}$ School of Mechanical Science and Engineering, Huazhong University of Science and Technology, Wuhan 430074, China
${ }^{2}$ Dongfeng Liuzhou Motor Co., Ltd., Liuzhou 545005, China
${ }^{3}$ School of Mechanical and Electrical Engineering, Guilin University of Electronic Technology, Guilin 541004, China
}

Correspondence should be addressed to Shuilong He; xiaofeilonghe@163.com and Weiguang Zheng; weiguang.zheng@ foxmail.com

Received 25 June 2020; Revised 16 September 2020; Accepted 29 September 2020; Published 21 October 2020

Academic Editor: Yanxue Wang

Copyright (c) 2020 Enyong Xu et al. This is an open access article distributed under the Creative Commons Attribution License, which permits unrestricted use, distribution, and reproduction in any medium, provided the original work is properly cited.

\begin{abstract}
The vibration level of a cab affects the passenger's ride comfort and safety significantly. It is of great importance to control the vibration level of cabs under various driving conditions. The associated vibration transfer paths of cabs are studied by using a hierarchical analysis method of a parameter index. The multiobjective design analysis is carried out by using the multiparameter joint optimisation design. Further, the optimal control of the cab vibration level is obtained from a full-condition simulation environment. Additionally, a multibody vehicle model is established. The simulation analysis under multiple working conditions is conducted. The optimal parameter distribution of the cab mounting structure was established by analysing the influence of the design parameters and experimental verification. This greatly improves the comfort of the cab.
\end{abstract}

\section{Introduction}

Peoples' requirements for the safety and comfort of commercial vehicles are becoming more stringent due to an improvement in living conditions. NVH (noise, vibration, and harshness) [1-3] is an important evaluation index to measure the level of vehicle comfort. This includes the performance impact of vibration, noise, and other related aspects. The vibration of the cab system directly affects the comfort and safety of the vehicle from its direct contact with the body. Excessive vibration will not only directly affect the comfort of driving and the physical and mental health of the human body. It will also strengthen the wear and tear of cab system parts and reduce the service life of the parts. Additionally, commercial vehicles are the main model of logistics transportation and often run for a long distance, at high speeds, and for a long time. Therefore, more attention should be paid to the comfort and safety of the vehicle. Longterm and continuous strong vibrations are also likely to affect the driver's physical and mental health and evaluation of the driving state of the car body. This might lead to traffic accidents [4-6]. Therefore, the research on vibration control of heavy commercial vehicle cabs is important for the engineering application prospect in today's logistics and highspeed era.

Many scholars have studied different design methods [7-11] of structural parameters of cab systems to improve cab vibrations, analysing balance, stability, and safety of cab systems. The most typical methods include the transfer path analysis method [12, 13], the fuzzy control method [14-16], and modal analysis method $[17,18]$ and so on. Chen et al. [19] proposed a two-level TPA model [20-22] to determine the causes of the cab's higher vibration level. Sun and Zhang [23] proposed that researchers consider the absolute displacement of the pitch motion of cabs beyond the traditional absolute accelerations. This improved the indications of the ride comfort for the suspended cab. Wu et al. [24] uses the finite element method and modal analysis method to establish the cab model and study the cab structure attributes. The human operational comfort was improved by 
optimising the cab structure. Additionally, the equivalent simple model often makes the objective analysis more accurate. At the same time, it can improve the efficiency and stability of the analysis to achieve better design results. For example, Zhao et al. [25] presented a four degree-of-freedom seat-cab-coupled system model and he proposed a new method of hybrid modelling of seat-cab coupled systems to achieve the optimal design of seat suspension and cab suspensions. This further improved the ride comfort of vehicles. Hansson [26] describes a model for the optimisation of parameters describing the characteristics of a passive nonlinear cab suspension. This minimises the total vibration load on the driver.

However, the original diagnosis method of cab vibration is complex and limited in its working conditions. There is also a lack of research on the effect of parameters on cab vibration. The analytic method of hierarchical index analysis can be proposed to improve the simplicity of the diagnosis analysis. This would simplify the parameters of the vibration damper on the vibration transmission path [27-31]. Additionally, original methods have a good application effect and convergence for local research objects or limited parameters. However, it is difficult to obtain good global convergence and an implementation effect for multisystem objects, complex matching, and the screening of parameters. Therefore, it must be organised the coordination between multisystems and multiparameters. The method of index decomposition can decompose the whole system, explore the parameter flow relationship on the local subsystem, and reduce the number of parameters analysed.

The rest of this paper is organised as follows. In Section 2, the parameter index method is applied to establish the parameter hierarchical interaction model. Then, Section 3 studies the vibration transmission path of cabs. The multibody vehicle model is established in Section 4. Additionally, the vibration coupling characteristics of cabs were analysed. The simulation under multiple driving conditions is conducted in Section 5. Furthermore, the modal analysis of the subsystem related to cabs is analysed in Section 6 . Lastly, the parameter cab suspension system is designed in Section 7, and the conclusions are given in Section 8.

\section{Establishment of Parameter Hierarchical Interaction Model}

From the design level, the vibration acceleration response at the cab seat can be taken as the design index of the vibration control. A hierarchical analysis method of parameter index is proposed. It will divide the expected value of products into the system model of each subset. Then, the interactive properties can be studied among the subsystems. Its main features are given as follows.

2.1. Coordination and Dispersion Characteristics of the Subsystem. The vibration transfer interference and resonance effect between subsystems will affect the vibration comfort and smoothness of the cab. Therefore, it is necessary to consider balancing the relationship between the excitation and subsystems, reducing or eliminating the resonance effect, and improving the damping capacity of the subsystem.

2.2. Deep Decomposition Characteristics of System. The index decomposition of a subsystem must study the parameter attributes of subsystem components deeply. It should further analyse the influence trend and effect of the parameters of the component layer on the index quantity of the subsystem decomposition.

\subsection{Parameter Influence under Multiple Working Conditions.} The influence of the subsystem parameters on the whole vehicle level index under multiple working conditions is studied. The best adjustment trend of parameters under each working condition is analysed, and the best parameter distribution value is obtained.

Considering the above features, the model of parametric decomposition method can be summarized in Figure 1.

The following refers to the parameter hierarchical interaction model shown in Figure 1 above. Among them, $I_{1}^{U}$ and $I_{1}^{L}$ represent the actual vibration response and expected vibration response between the vehicle level and decomposition level, respectively. Further, $I_{\text {partl }}$ and $I_{\text {part }}$ is the systemlevel vibration response and the expected vibration response on the decomposed part level, respectively. Under the initial condition, $I_{\text {part }}^{U}$ and $I_{\text {part }}^{L}$ are the system-level vibration response and the expected vibration response on the decomposed part level, respectively. Under the multidynamic condition, $x$ is the system parameter design variable. According to analyse the combination relationship of commercial vehicle system components and the decomposition direction of "excitation source transfer path response target". These sources suggest that vehicle vibration is decomposed into a vehicle system and a vehicle subsystem. To realize the exchange and adjustment of vibration transmission variables between systems, the obtained response model of vehicle level and system-level indicators is shown in Figure 2. This demonstrates the exchange and adjustment of vibration transmission variables between systems where $R$ represents the mathematical model of vibration response, and $f$ and $g$ represent equality and inequality constraints of parameter, variables, respectively. Further, $\xi_{R}$ and $\xi_{V}$ are the deviation of reference optimisation indexes. Based on the established response model, the vibration transmission path of cabs is researched. The influence of parameter variables on cab vibrations is also analysed.

\section{Analysis of Vibration Transmission Path Associated with Cabs}

Under the exciting action of the road to tyre, the vibration frequency response is produced at the relevant evaluation point of the cab. As shown in Figure 3, the main vibration transfer path can be expressed as

(1) Tyre centre-the suspension upper fulcrum-cab suspended lower fulcrum-cab centre of mass-driver's centre of mass 


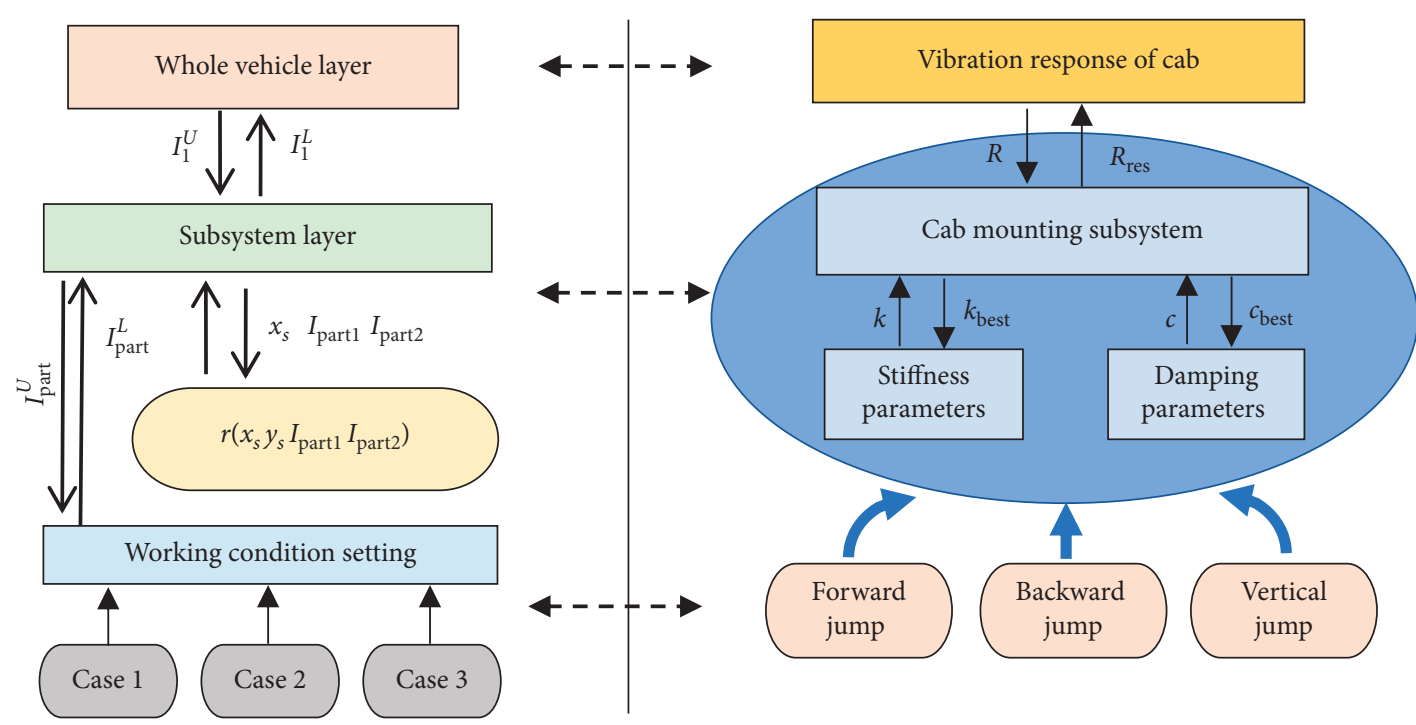

FIgURe 1: Parameter hierarchical interaction model.

Vehicle layer

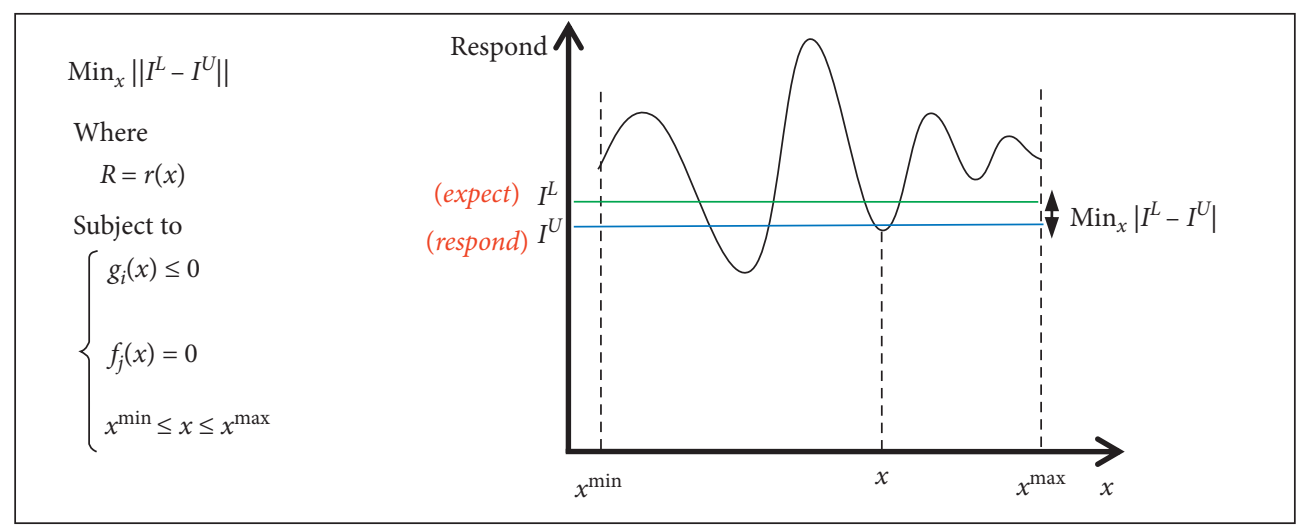

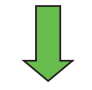

Subsystem layer

Minimize $_{x}\left|I^{L}-I^{U}\right|+\xi_{R}+\xi_{v}$
Where $R_{\text {part }}=r\left(I^{U}, I_{\text {part }}^{U}, I_{\text {part } 1}, x\right), \sum_{k \in C}\left\|I_{\text {part }}^{L}-I_{\text {part }}^{U}\right\|=\xi_{R}, \sum_{k \in C}\left\|I_{\text {part 1 }}-I_{\text {part } 2}\right\|=\xi_{v}$
Subject to
$g(R, x) \leq 0, f(R, x)=0$
$x_{\min } \leq x \leq x_{\max }$

FIgURE 2: Interaction of parameter indexes between the vehicle level and subsystem level.

(2) Tyre centre-the suspension upper fulcrum-the leaf spring front fulcrum-front mount lower fulcrumfront mount upper fulcrum-cab centre of massdriver's centre of mass
The engine is another main exciting source of commercial vehicles. It may cause abnormal vibration of the parts connected to the frame. This results in huge noise and vibration interferences in the cab. The vibration is transmitted through 


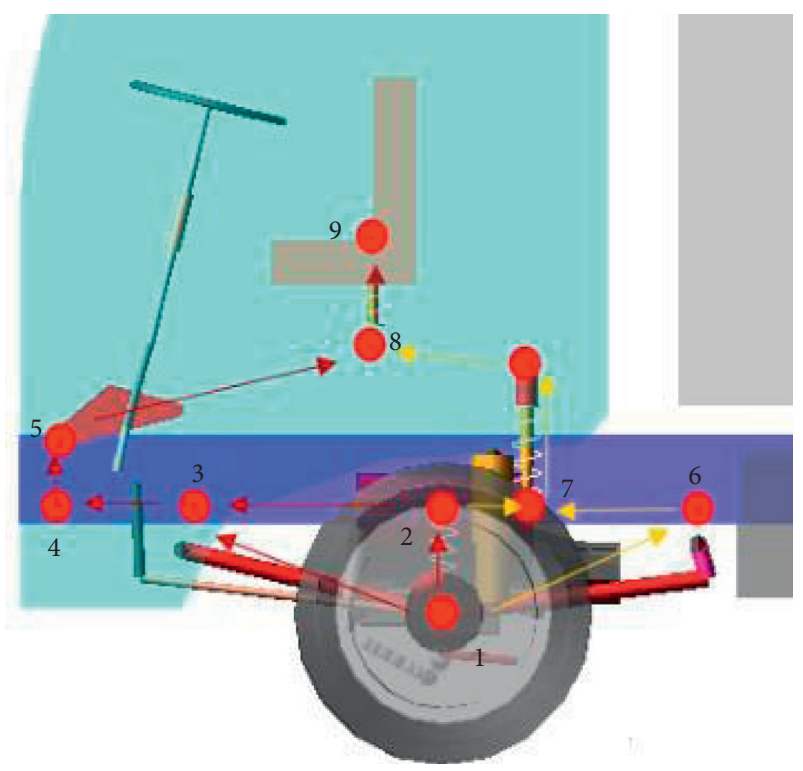

FIGURE 3: Vibration transfer path from tyre excitation. 1-tyre centre, 2-the upper suspension fulcrum, 3-the leaf spring front fulcrum, 4-front mount lower fulcrum, 5-front mount upper fulcrum, 6-plate spring rear fulcrum. 7-cab suspended lower fulcrum, 8-cab centre of mass, and 9-driver's centre of mass.

the engine, the engine mount, and the cab mount system until it finally reaches to the cab. This greatly affects the comfort of the cab. It is necessary to study and analyse the system parameter effects on the response transfer path under different working conditions. This would improve the damping effect of the dampers on the vibration transfer path.

\section{Establishment of Vehicle Model}

According to the arrangement of the real vehicle, the cab subsystem, the frame subsystem, the powertrain subsystem, the frame subsystem, and other subsystems are decomposed and established.

Concerning the layout of the vehicle, the cab subsystem, frame subsystem, powertrain subsystem, frame subsystem, and other subsystems are established. The real car model is shown in the below figure. Additionally, the corresponding bench structures are established at the bottom of the four wheels of the car body. They are used to exert vibration and impact excitation on the front and rear tyres, respectively, as shown in Figure 4.

Based on the vehicle model established by ADAMS (Automatic Dynamic Analysis of Mechanical Systems) software, the frequency sweep excitation signal with a frequency of $1 \sim 50 \mathrm{~Hz}$ is applied to the four the bench structures [32]. It separately beats at the front bridge, the rear bridge, and the vertical jump. After the complete constraint was applied to the point between the wheel and the bench, the acceleration response of the cab is tested.

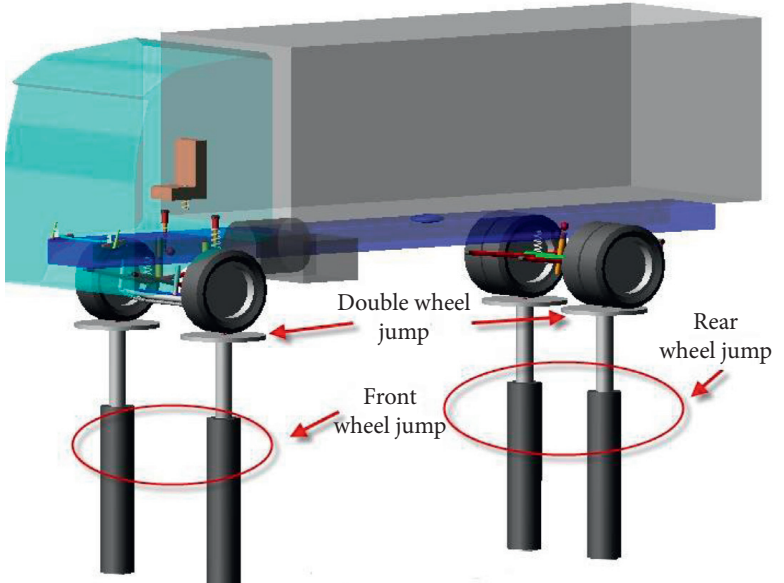

FIgURE 4: The vehicle multibody model under the incentive pedestal.

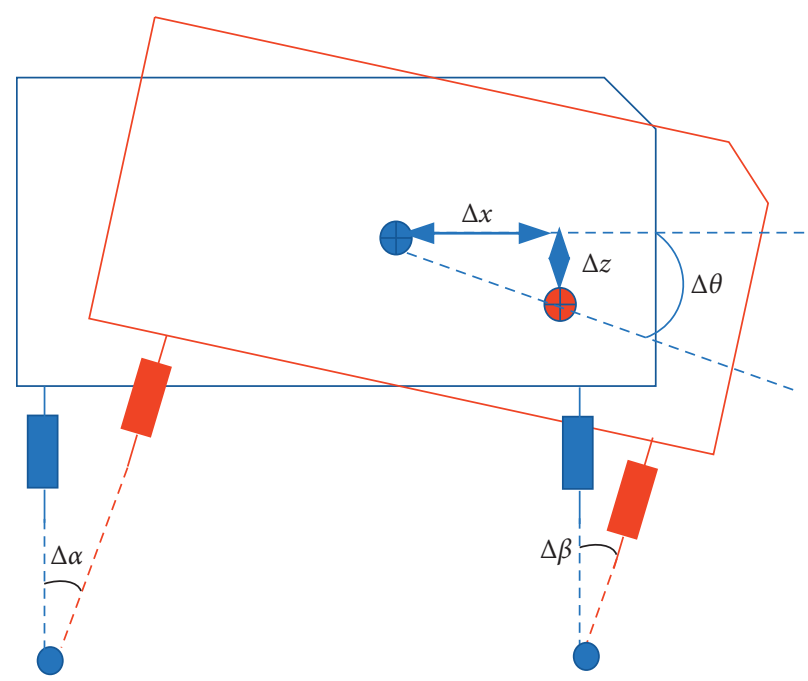

FIgURE 5: Schematic diagram of pitch motion of cab.

\section{Analysis of Vibration Coupling Characteristics of Cab}

Under vibration transmission excitation of the frame, the front and back mount arm of the cab will generate a deflection angle between the initial equilibrium position and the initial equilibrium position. This is assuming that the angle between the front suspension motion and rear suspension motion is $\Delta \alpha$ and $\Delta \beta$, respectively.

The influence of steering constraint of the cab mounting steering mechanism causes the vibration displacement to be generated in other directions. This includes a vertical displacement $\Delta z$, horizontal displacement $\Delta x$, and lateral displacement. Therefore, the vibration response coupling problem exists in cabs in every direction. This requires detailed analyses and research. 


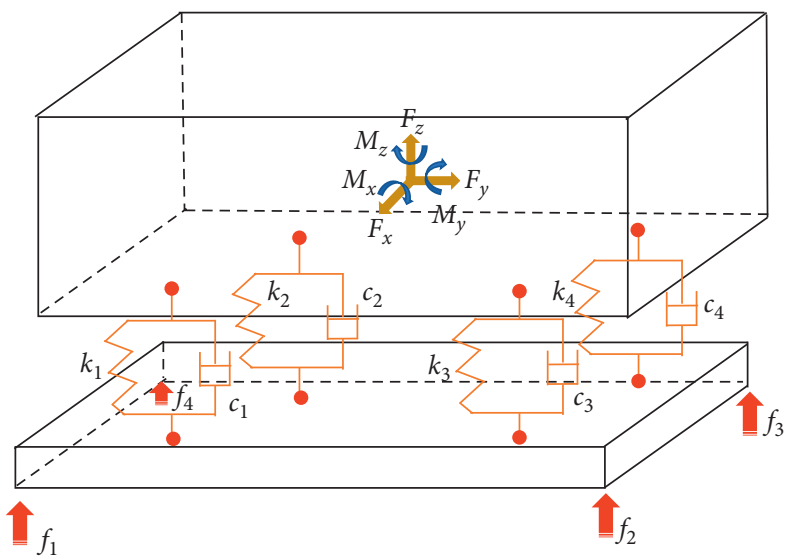

Figure 6: Dynamic response schematic diagram of the cab.

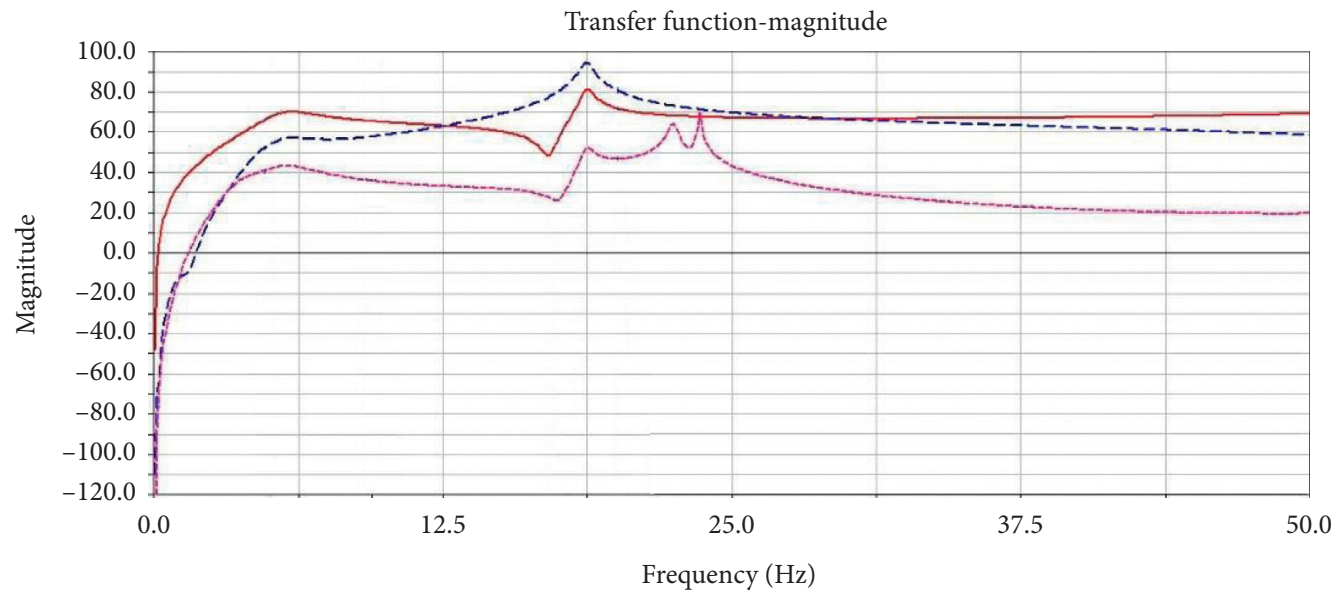

_ Vibration analysis: sum of all inputs output $Z_{-} Z_{-}$transfer functions

- - - Vibration analysis: sum of all inputs output _ $X_{-}$transfer functions

..... Vibration analysis: sum of all inputs output $\_Y_{-}$transfer functions

(a)

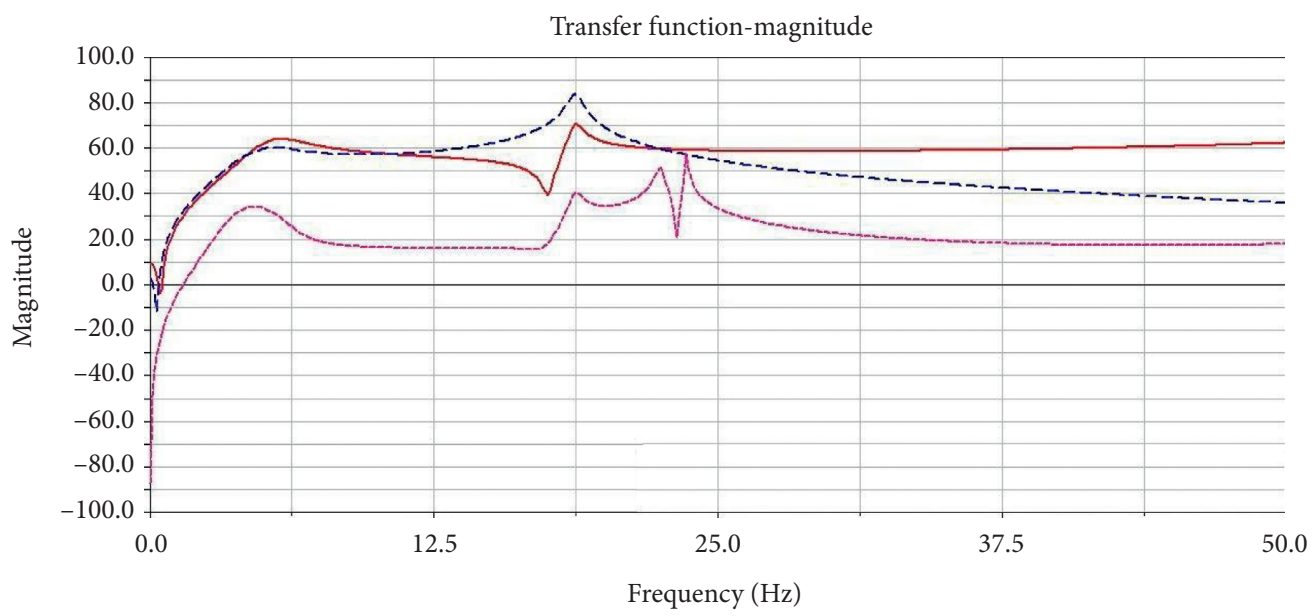

_ Vibration analysis: sum of all inputs output $Z_{-}$transfer functions

- - - Vibration analysis: sum of all inputs output $X_{-}$transfer functions

Vibration analysis: sum of all inputs output $Y_{-}$transfer functions

(b)

FIGURE 7: Continued. 


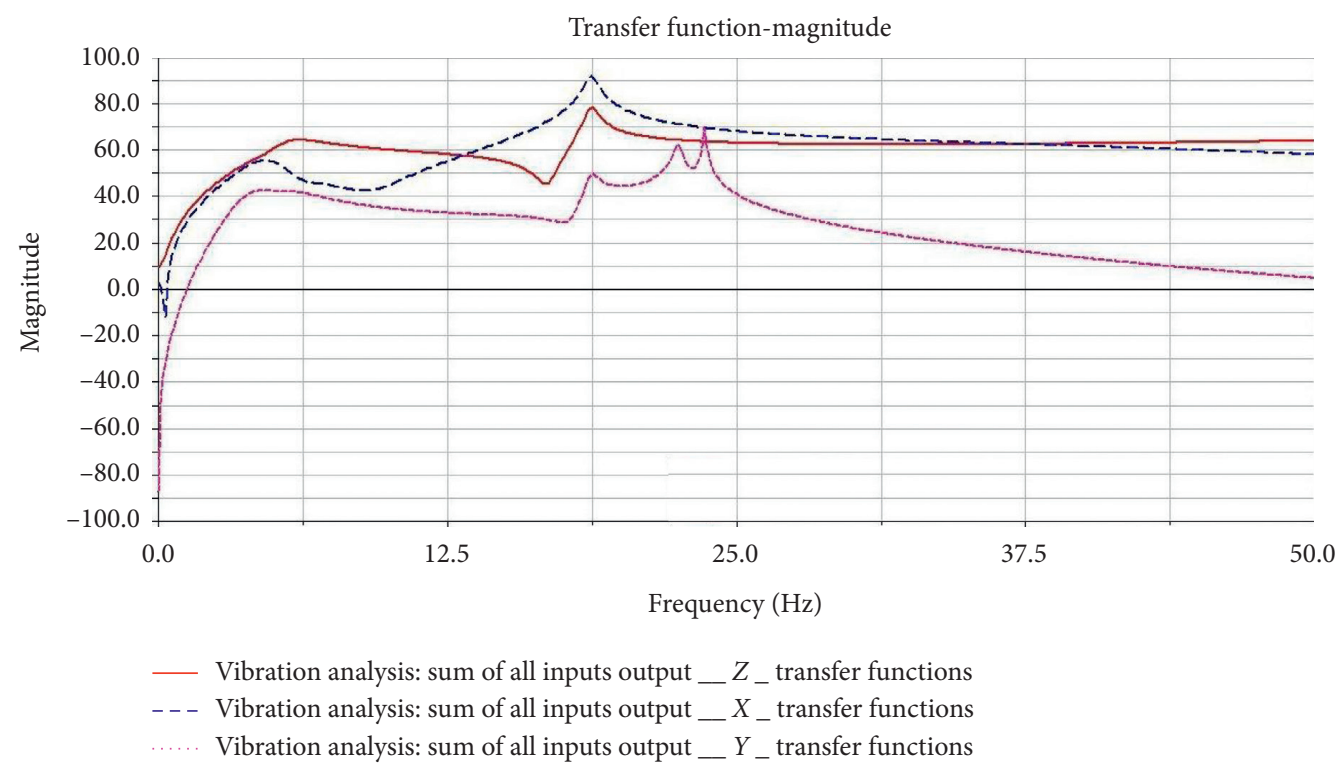

(c)

FIGURE 7: Diagram transfer function diagram under different working conditions. (a) Vibration transfer function diagram under the vertical working condition. (b) Diagram of Vibration transfer function under the back-jump working condition. (c) Vibration transfer function diagram under forward-jump condition.

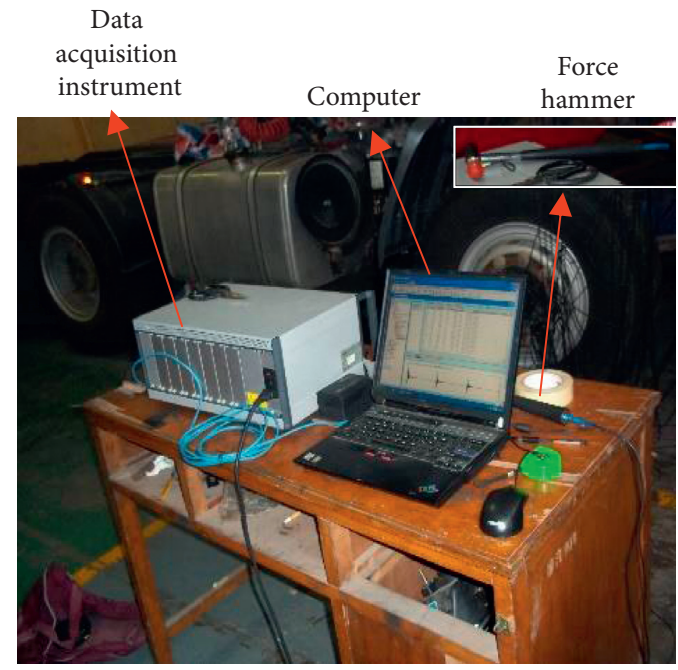

(a)

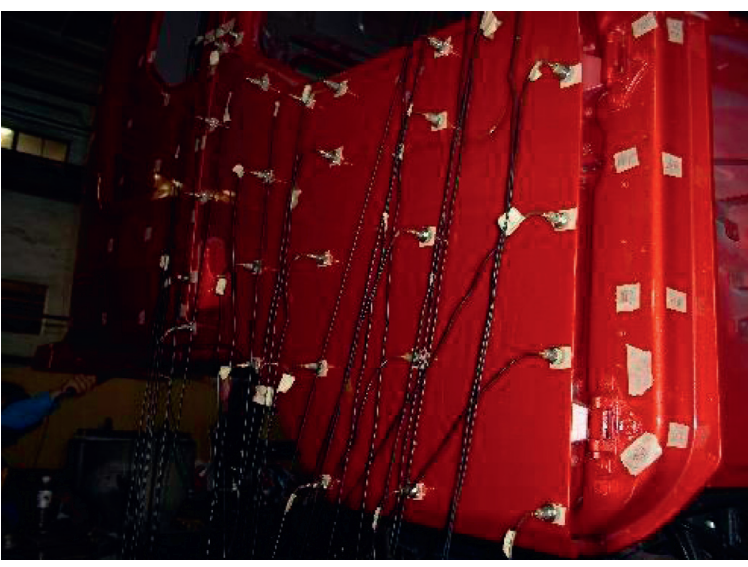

(b)

FIGURE 8: The experimental modal testing equipment and the location of measuring points. (a) Experimental acquisition instrument. (b) Arrangement of measuring points for cab body.

\subsection{Driving Analysis of Cab under Multicondition}

5.1.1. Analysis on Vibration Principle of Cab. Referring to Figure 6, the condition of driving assumes that the exciting force transmitted by the vibration at the bottom of the cab mount is $\left[\begin{array}{lll}F_{1} & F_{2} & F_{3}\end{array}\right]$.

The response force at the centroid position of the cab can be expressed as $\left[\begin{array}{llllll}F_{x} & F_{y} & F_{z} & M_{x} & M_{y} & M_{z}\end{array}\right]$ following the vibration absorption treatment of the cab mounting damping parameters. Among them, the excitation force is assumed as the excitation that contained the same amplitude and different periodic. This simulates different vibration response behaviours. Its expression can be set as

$$
\begin{aligned}
& f_{1}=A \sin \left(\omega t+\varphi_{1}\right), \\
& f_{2}=A \sin \left(\omega t+\varphi_{2}\right), \\
& f_{3}=A \sin \left(\omega t+\varphi_{3}\right), \\
& f_{4}=A \sin \left(\omega t+\varphi_{4}\right) .
\end{aligned}
$$




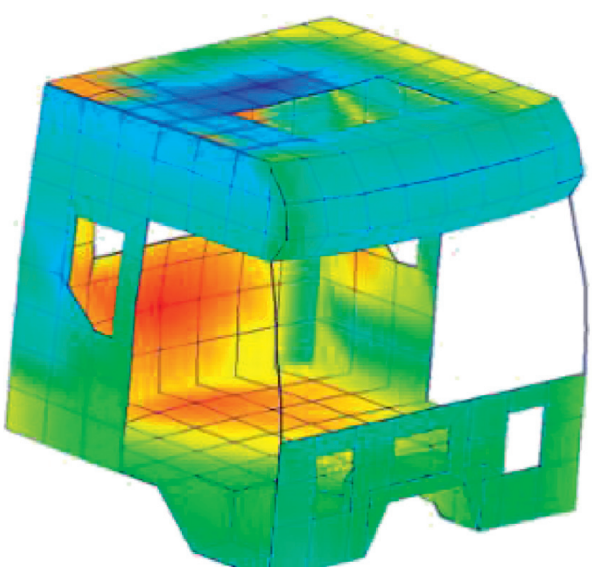

(a)

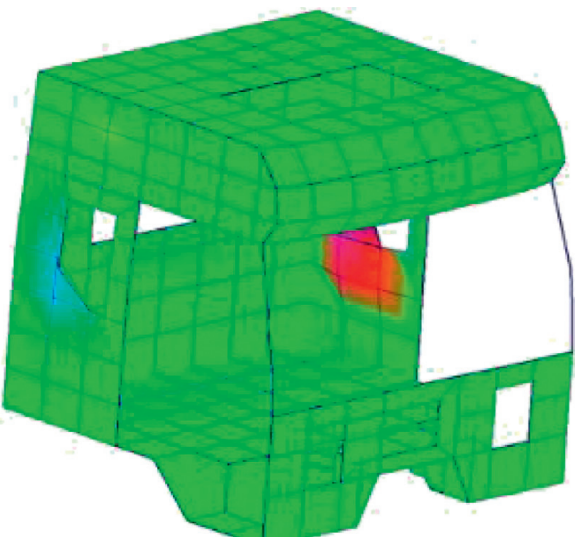

(c)

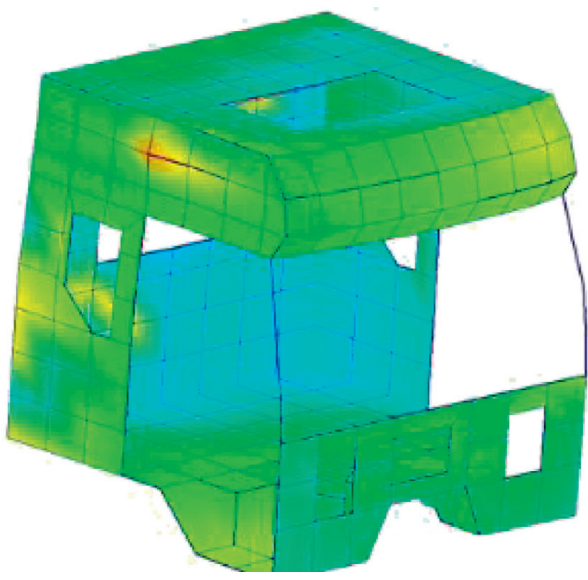

(e)

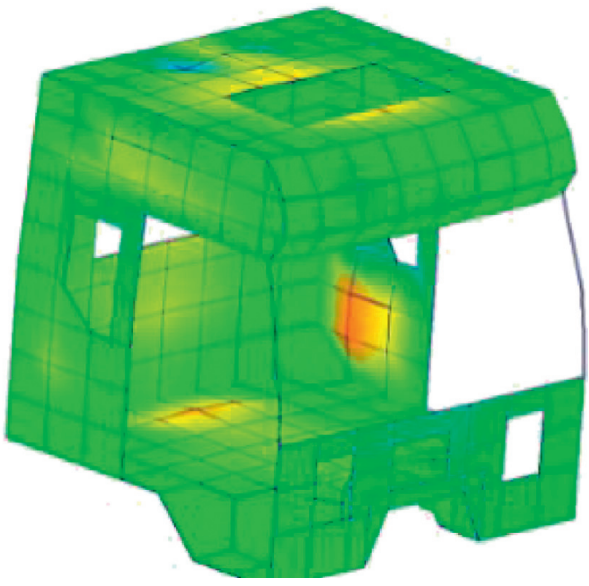

(b)

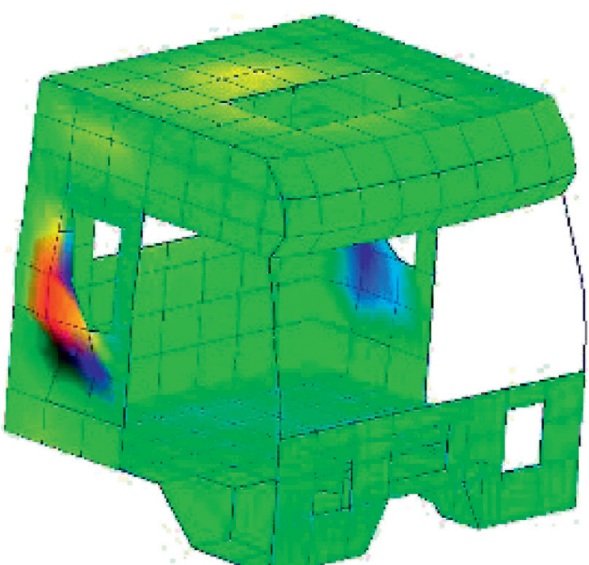

(d)

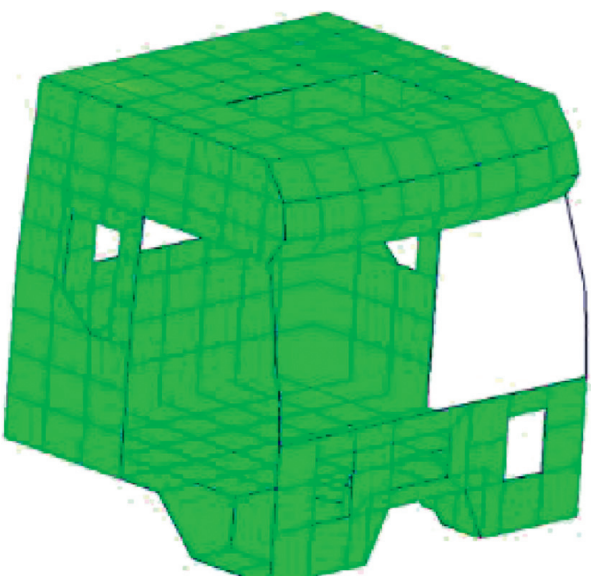

(f)

Figure 9: Experimental modal test results of cab skeleton. (a) 1th mode $(21.23 \mathrm{~Hz})$. (b) 2 nd mode $(24.73 \mathrm{~Hz})$. (c) $3 \mathrm{rd} \mathrm{mode}(28.14 \mathrm{~Hz})$. (d) 4th mode $(30.45 \mathrm{~Hz})$. (e) 5 th mode $(32.11 \mathrm{~Hz})$. (f) 6 th mode $(32.76 \mathrm{~Hz})$.

(i) Pre jump condition and back jump condition. There exists a signal phase constraint relation between each force:

$$
\begin{aligned}
& \varphi_{2}=\varphi_{3}, \\
& \varphi_{1}=\varphi_{4}, \\
& \varphi_{1}=\varphi_{2} \pm 180^{\circ} .
\end{aligned}
$$

Force $F_{2}$ and force $F_{3}$ are equal currently, and force $F_{1}$ and force $F_{4}$ are identical. Still, there exists a phase angle difference of 180 degrees between force $F_{1}$ and force $F_{3}$. At this point, the cab body will maintain a certain delay pitch response.

(ii) Vertical jump condition. Aiming at the vertical vibration response of $\mathrm{cab}$, the signal phase constraint relation between each force can be expressed as: 


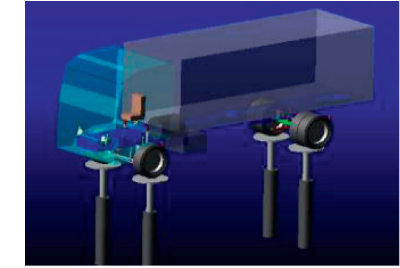

Upper and lower direction of cab and front axle $(1.3 \mathrm{~Hz})$

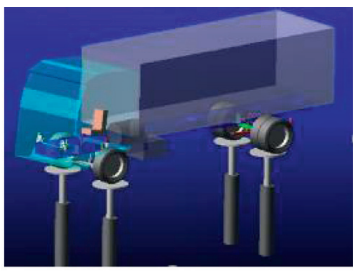

Upper and lower direction of rear suspension of $\mathrm{cab}(1.8 \mathrm{~Hz})$

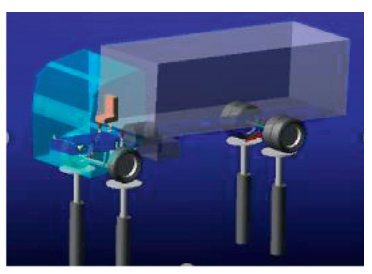

Upper and lower direction of rear axle $(2.7 \mathrm{~Hz})$

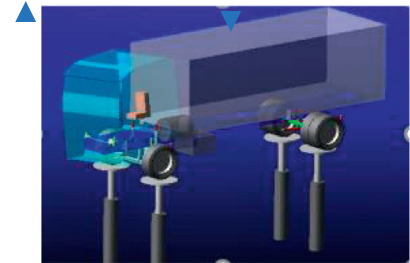

Left and right direction of the cab $(1.5 \mathrm{~Hz})$
$\Delta$

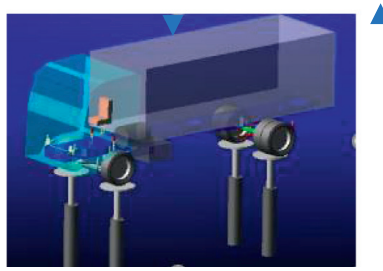

Upper and lower direction of seat $(2.3 \mathrm{~Hz})$

Figure 10: Partial modal shapes and frequencies of body parts.

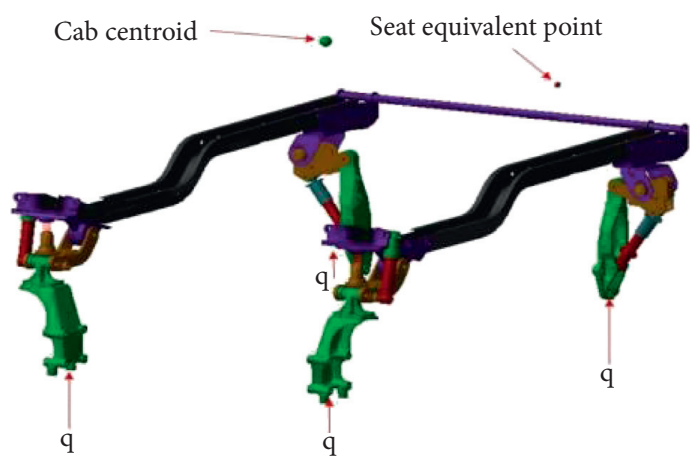

FIgURE 11: Simplified cab suspension combination model.

$$
\varphi_{2}=\varphi_{3}=\varphi_{1}=\varphi_{4}
$$

At this time, the excitation vibration signals with equal amplitudes and phases, guaranteeing the stability of the cab's vertical vibration.

5.1.2. Establishment of Dynamic Equation for Cab. Based on the analysis of mechanical principle, the generalized dynamic equation of vibration dynamics of the cab is as follows:

$$
M \ddot{X}+C \dot{X}+K X=\{f(t)\},
$$

where $M$ represents the mass of the cab mounting coupling system, $C$ and $K$ denote the equivalent damping and stiffness of the cab mounting system, $X$ represents the spatial generalized displacement, and $f(t)$ represents the exciting force. Considering the dynamic response schematic diagram of cabs shown in Figure 1, the parameters are as follows:

$$
\begin{aligned}
& M=\left[\begin{array}{lll}
m_{0} & \\
& & m_{1}
\end{array}\right], \\
& C=\left[\begin{array}{llll}
c_{1} & & \\
& c_{2} & & \\
& & c_{3} & \\
& & & c_{4}
\end{array}\right], \\
& K=\left[\begin{array}{llll}
k_{1} & & & \\
& k_{2} & & \\
& & & \\
& & & \\
& & & k_{4}
\end{array}\right] .
\end{aligned}
$$

The vibration responses of a single DOF model can be analysed when considering the inherent frequencies and vibration modes of cab structures. This is mainly the no damping model or small damping model. On the one hand, equation (4) can be rewritten as follows when considering the no damping model: 


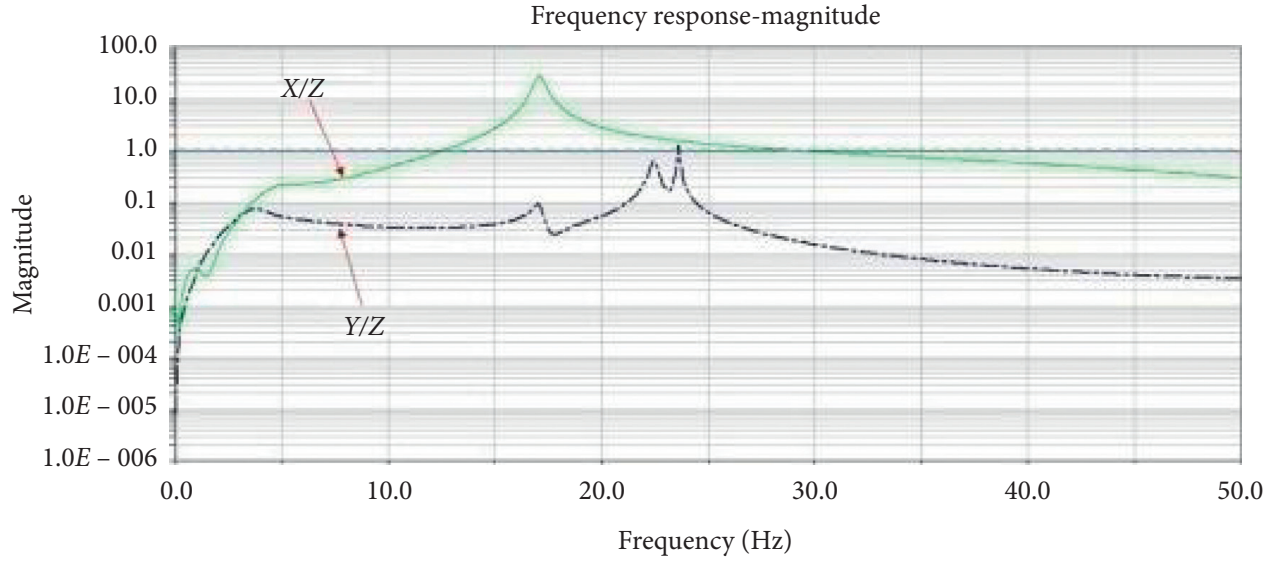

(a)

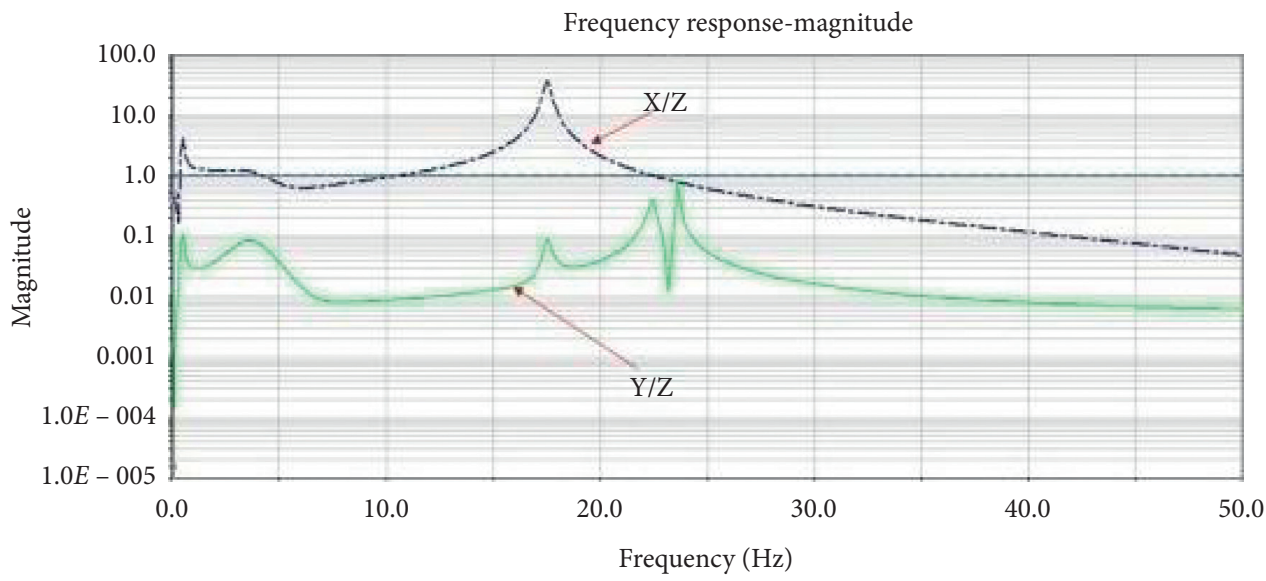

(b)

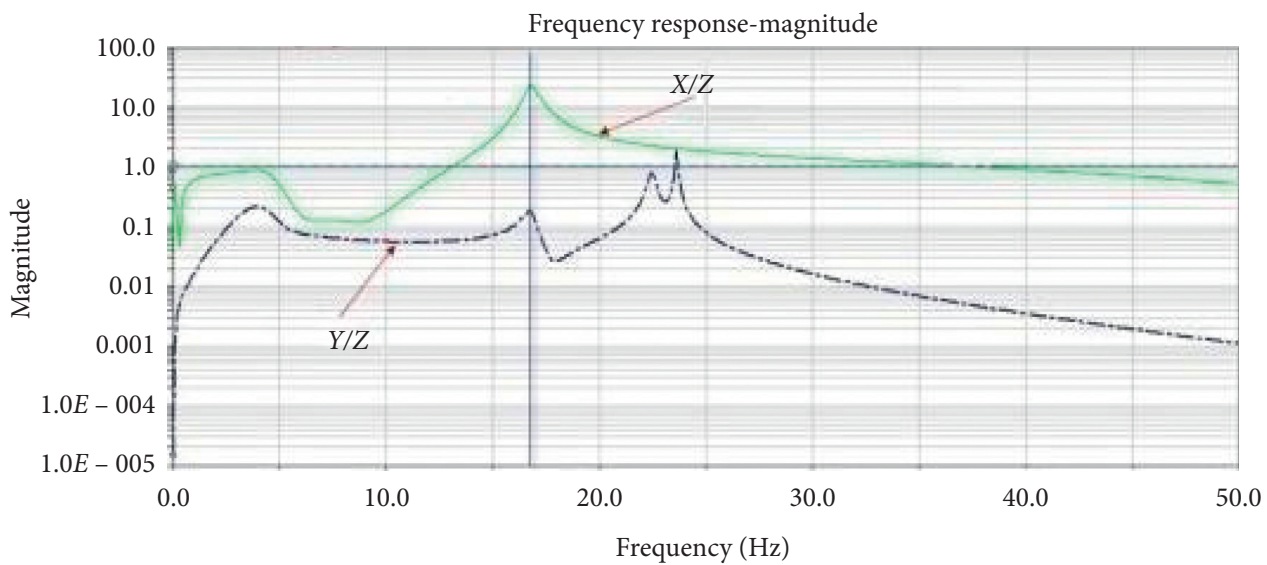

(c)

FIgURE 12: The frequency responds in (a) vertical motion, (b) back jump motion, and (c) forward jump motion. 


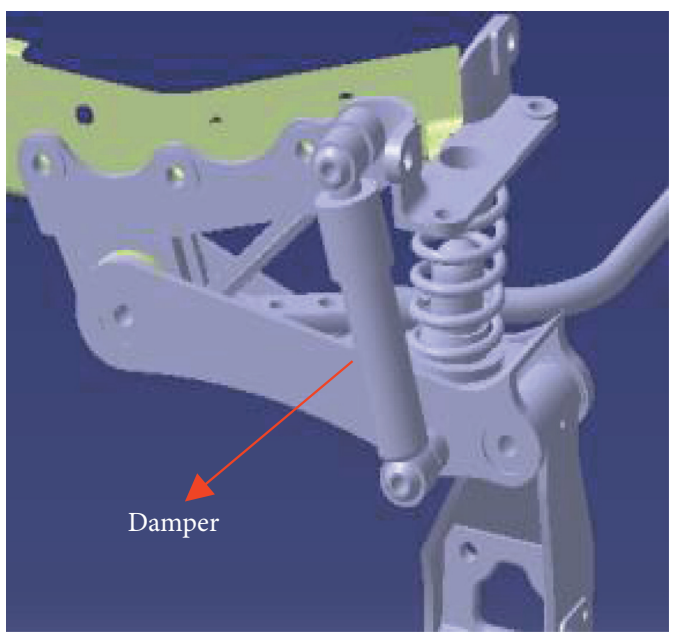

(a)

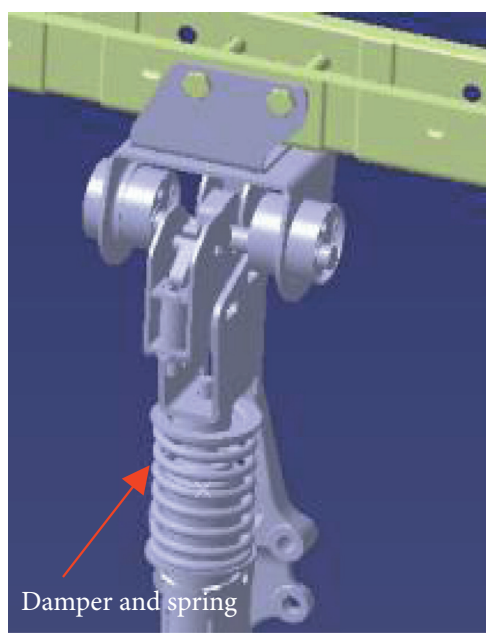

(b)

FIgURE 13: Front and rear suspension structure. (a) Rear mount. (b) Front mount.

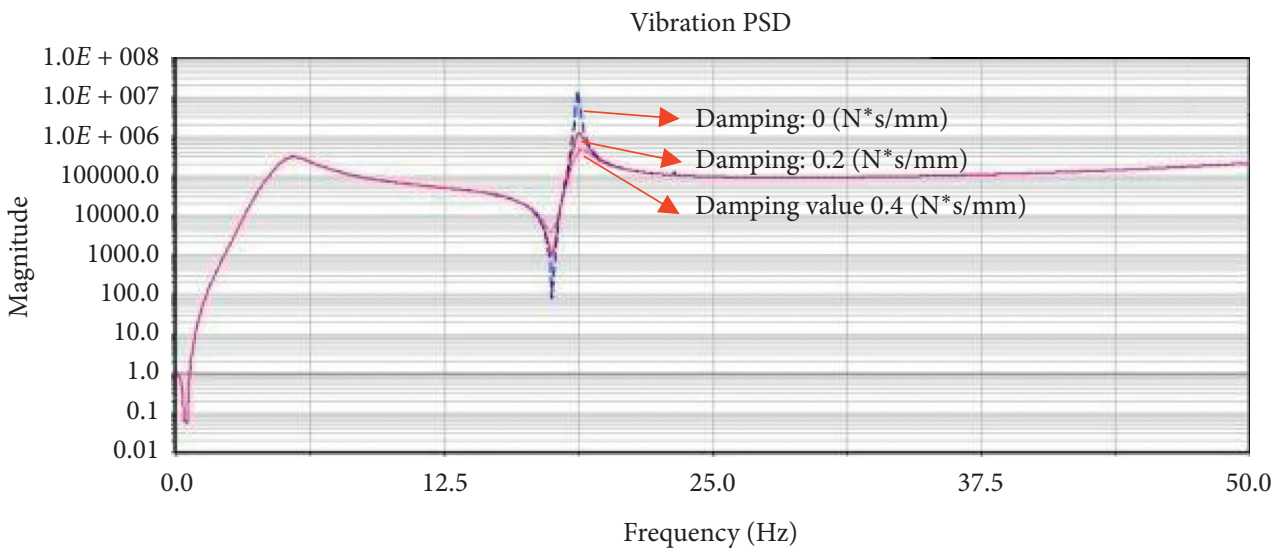

_- Vibration analysis: output $1 \_$PSD

- - - Vibration analysis: output 2_PSD

..... Vibration analysis: output 3_ PSD

(a)

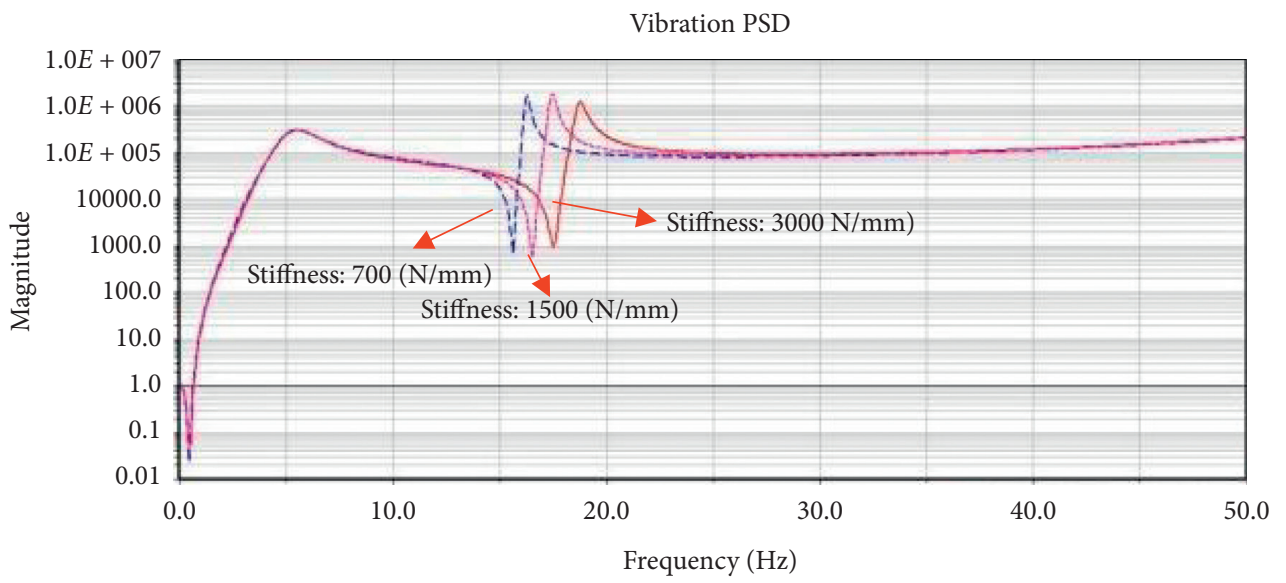

_ Vibration analysis: output 1_PSD

- - - Vibration analysis: output 2_PSD

...... Vibration analysis: output 3_PSD

(b)

FIGURE 14: Effect of stiffness and damping of front suspension of the cab on PSD. (a) PSD curve of cab centroid acceleration under damping fine adjustment. (b) PSD curve of cab centroid acceleration under stiffness fine-tuning. 


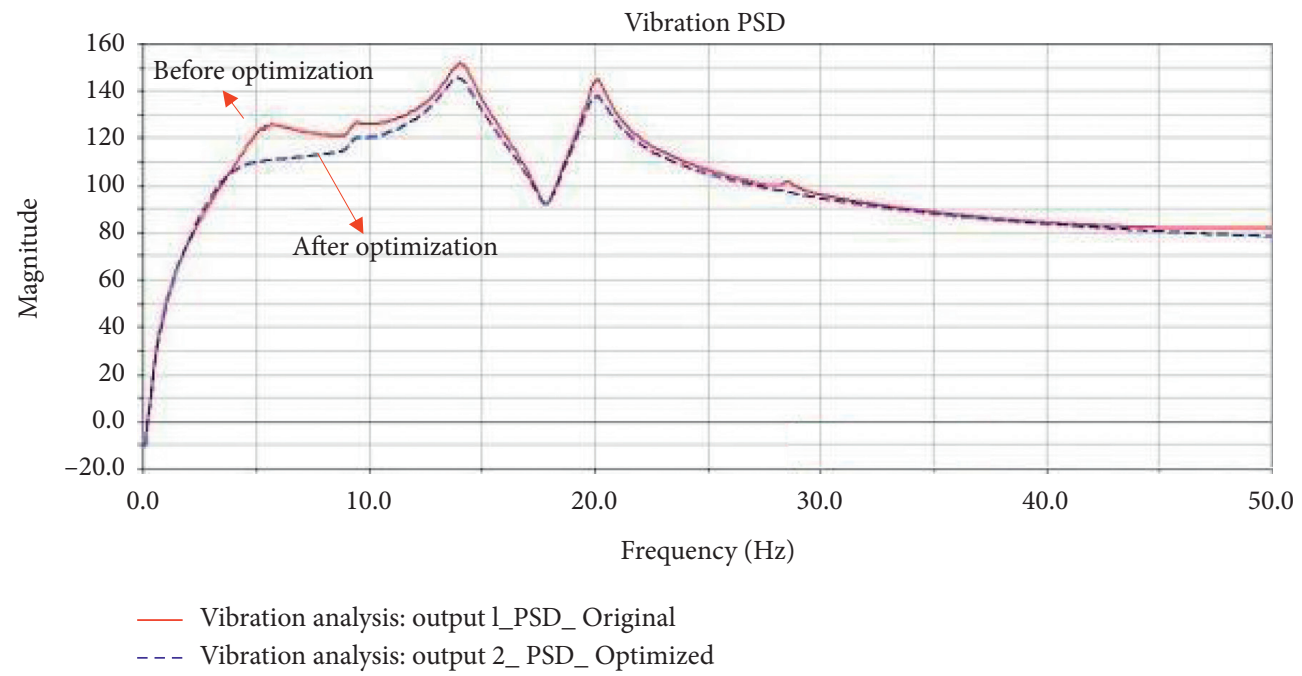

FIGURE 15: PSD curve of cab centroid acceleration before and after damping optimisation.

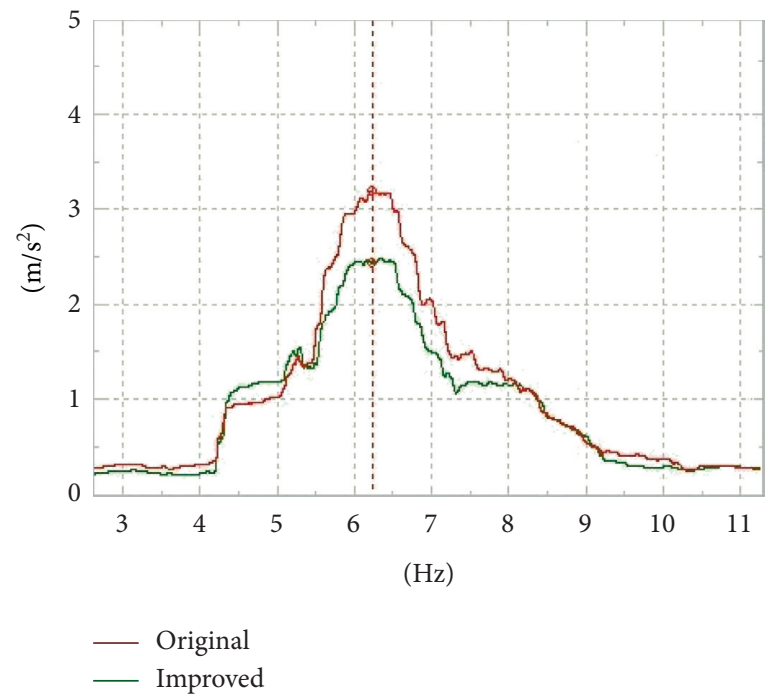

(a)

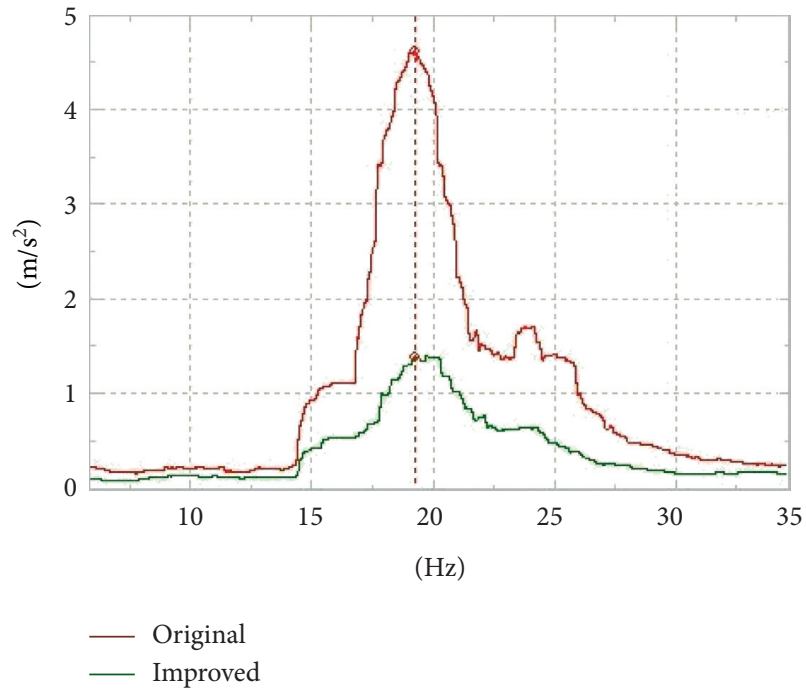

(b)

FIGURE 16: Spectrum of vibration acceleration of driver's seat when driving speed reached (a) $35 \mathrm{~km} / \mathrm{h}$ and (b) $105 \mathrm{~km} / \mathrm{h}$.

$$
M \ddot{X}+C \dot{X}+K X=0
$$

If $p$ is defined as the attenuation coefficient and $\omega$ is the inherent frequency of the cab mount system, then the above formula can be further simplified:

$$
\begin{aligned}
\ddot{x}+2 p \dot{x}+\omega^{2} z & =0, \\
2 p & =\frac{C}{m}, \\
\omega^{2} & =\frac{K}{M} .
\end{aligned}
$$

Using the formula mentioned above, the formula of the natural frequency of a cab suspension system without damping can be expressed as follows:

$$
f=\frac{\omega}{2 \pi}=\frac{1}{2 \pi} \sqrt{\frac{K}{M}} .
$$

On the other hand, when considering the small damping effect of the cab suspension system. From this, the vibration response of the cab suspension damping depends on the damping ratio of the coupling system mainly. Its expression can be conveyed as follows: 
TABLE 1: Wheel rotation frequency at each speed.

\begin{tabular}{lccc}
\hline$r(\mathrm{~m})$ & $V(\mathrm{~km} / \mathrm{h})$ & $f_{1}(\mathrm{~Hz})$ & $f_{2}(\mathrm{~Hz})$ \\
\hline 0.4949 & 30 & 2.68 & 5.36 \\
0.4949 & 35 & 3.13 & 6.25 \\
0.4949 & 40 & 3.57 & 7.15 \\
0.4949 & 45 & 4.02 & 8.04 \\
0.4949 & 50 & 4.47 & 8.93 \\
0.4949 & 55 & 4.91 & 9.83 \\
0.4949 & 60 & 5.36 & 10.72 \\
0.4949 & 65 & 5.81 & 11.61 \\
0.4949 & 70 & 6.25 & 12.51 \\
0.4949 & 75 & 6.70 & 13.40 \\
0.4949 & 80 & 7.15 & 14.29 \\
0.4949 & 85 & 7.59 & 15.19 \\
0.4949 & 90 & 8.04 & 16.08 \\
0.4949 & 95 & 8.49 & 16.97 \\
0.4949 & 100 & 8.93 & 17.87 \\
0.4949 & 105 & 9.38 & 18.76 \\
\hline
\end{tabular}

$$
\xi=\frac{P}{\omega}=\frac{C}{2 \sqrt{m K}} .
$$

At this time, the coupling system of the cab suspension mainly vibrates with inherent frequency $\sqrt{\omega^{2}-p^{2}}$. Its vibration amplitude is attenuated according to $e^{-\mathrm{pt}}$. Its corresponding damping cab mount system can be expressed as follows:

$$
\omega_{r}=\sqrt{\omega^{2}-p^{2}}=\omega \sqrt{1-\xi^{2}} .
$$

In the vehicle engineering field, the natural frequency values of small damping and natural frequencies without damping might approximate $\left(\omega \approx \omega_{r}\right)$. Therefore, the influence of small damping can be ignored, considering the problem of cab structure resonance. It can further be analysed the structure frequency of the cab's structure.

5.2. Simulation under Multiple Driving Conditions. To simulate the response behaviour of the whole vehicle (such as front jump, back jump and so on), the frequency sweep excitation is applied to the front wheel and rear wheel simultaneously and separately. This simulates the whole vehicle, passing through the brake belt. According to the simulation results, the vibration transfer function of the cab seat is shown in Figure 7.

According to Figure 7, the system transfer rate is the highest ranging from $5.3 \mathrm{~Hz}$ to $18.7 \mathrm{~Hz}$. At this time, it is referred to the wheel rotation frequency calculation formula. This can be expressed as follows:

$$
f_{w}=\frac{n \cdot V \cdot 10^{6}}{2 \pi r \cdot 3600},
$$

where $N$ represents the modal order, $V$ represents the driving speed, and $r$ indicates the wheel radius. After the calculation, the order frequency of the wheel at each speed is shown in Table 1. where $f_{1}$ represents the first-order tyre rotation frequency, and $f_{2}$ represents the second-order tyre rotation frequency. Table 1 shows that the wheel rotation frequencies are $6.25 \mathrm{~Hz}$ (first-order) and $18.76 \mathrm{~Hz}$ (second-order) when the drive shaft load speed reached $35 \mathrm{~km} / \mathrm{h}$ and $105 \mathrm{~km} / \mathrm{h}$, respectively. These findings are consistent with the peak frequency values in Figure 7.

The frequency value of the excitation frequency signal might be close to the natural frequency of the system structure. In this case, it is easy to cause a large peak vibration of the system. Therefore, the relationship between the frequency of input signal and structure natural frequency needs to be analysed.

\section{Modal Analysis of Subsystems}

6.1. Modal Analysis of Cab. The experimental modal test and analysis of the cab structure are carried out to ensure the accuracy of the cab model. In the modal experiment, there are two kinds of boundary conditions: free boundary and constrained boundary [33-35]. Between them, the free boundary means it is completely suspended in the air, does not have any Earth constraint, and has a rigid body mode and elastic mode. This can be realized by a rubber rope, sponge, and airbag during the test. The constraint boundary means that the structure is subject to a certain binding force without a rigid body mode. It only has an elastic mode. It can be fixed by a fixture or constrained according to the actual assembly state during the test. In this paper, the constrained boundary method is used for the experiments. Some measuring points and acquisition instruments are shown in Figure 8.

Combined with the mode value in Figure 9, the modal frequency value of the cab is far from the corresponding rotation frequency value. Therefore, the influence of the cab's resonance can be ignored.

6.2. Modal Analysis of Additional Subsystems on the Cab Body. Beyond the modal analysis results of the cab, it is necessary to analyse the structural modes of additional subsystems like the cab mounting system. The constraints between the car body and the excitation bench were set. Following this, the modal solver type is set to the static solver, and the solution step is set to 0.01 . The whole vehicle mode is obtained, as shown in Figure 10.

Figure 10 demonstrates that the frequency distribution of the front and rear suspension modes of the cab and the corresponding modal modes values ranges from 1 to $5 \mathrm{~Hz}$. This information is based on the whole vehicle modal analysis. Table 2 shows that there is little difference between the theoretical frequency calculation value and the simulation value of the front and rear cab mounting. This verifies the accuracy of the model.

The magnitude of the front and rear suspension frequencies reveals that the resonance response of the suspension structure caused by the frequency offset can be ignored. This is because there is a significant difference between the bias frequency and the actual wheel rotation 
TABLE 2: Modal frequency between simulation and theoretical calculation.

\begin{tabular}{lcc}
\hline Mode direction & Theoretical calculation frequency $(\mathrm{Hz})$ & Simulation frequency $(\mathrm{Hz})$ \\
\hline Pitch direction of front suspension of cab & 2.3 & 1.3 \\
Pitch direction of rear suspension of cab & 2.5 & 1.8 \\
The up and down direction of the seat & 2.5 & 2.3 \\
The up and down direction of the rear axle & 2.7 & 2.7 \\
\hline
\end{tabular}

TABLE 3: Optimum stiffness damping value of component layer.

\begin{tabular}{lccc}
\hline Mounting & Sprung mass $(\mathrm{kg})$ & Damping $(\mathrm{N} . \mathrm{s} / \mathrm{m})$ & Stiffness $(\mathrm{N} / \mathrm{mm})$ \\
\hline Front mount & 195 & 0.4 & 3000 \\
Rear mount & 144 & 0.2 & 2100 \\
\hline
\end{tabular}

excitation frequency. Therefore, the cab mounting parameters can be further studied and analysed to determine the influence of cab mounting parameters on the cab.

\section{Parameter Design and Verification}

The cab suspension decomposition subsystem's design response target, design variables, and constraint relationships can be summarized as follows:

$$
\begin{gathered}
R=r\left(c_{1}, c_{2}, c_{3}, c_{4}, k_{1} k_{2}, k_{3}, k_{4}\right), \\
\text { Minimize }\left\|R_{s}-R_{s_{0}}\right\| \sum_{k \in C}\left\|I_{1}^{L}-I_{1}^{U}\right\|=\xi_{R_{1}}, \sum_{k \in C}\left\|I_{2}^{L}-I_{2}^{U}\right\|=\xi_{R_{2}}, \sum_{k \in C}\left\|I_{3}^{L}-I_{3}^{U}\right\|=\xi_{R_{3}}, \sum_{k \in C}\left\|I_{4}^{L}-I_{4}^{U}\right\|=\xi_{R_{4}}, \\
\text { subject to } \quad \begin{array}{l}
c_{\min } \leq c_{1} \leq c_{\max }, c_{\min } \leq c_{2} \leq c_{\max }, c_{\min } \leq c_{3} \leq c_{\max }, c_{\min } \leq c_{4} \leq c_{\max }, \\
k_{\min } \leq k_{1} \leq k_{\max }, k_{\min } \leq k_{2} \leq k_{\max }, k_{\min } \leq k_{3} \leq k_{\max }, k_{\min } \leq k_{4} \leq k_{\max } .
\end{array}
\end{gathered}
$$

Among them, the vibration response acceleration values of the cab seat positions before and after parameter improvement are indicated by $R_{s_{0}}$ and $R_{s} . I^{U}$ and $I^{L}$ indicate the acceleration values of upper and lower fulcrum positions of a suspended position, respectively. $\xi_{R_{1}}, \xi_{R_{2}}, \xi_{R_{3}}$, and $\xi_{R_{4}}$ indicate deviations from response acceleration values for four suspended positions at upper and lower pivots. $c_{\min }$ and $k_{\min }$ indicate lower limit values for stiffness or damping parameters, respectively. Both $c_{\max }$ and $k_{\max }$ correspond to upper limit values.

The optimal design and analysis of the parameters are further conducted based on the determined cab mount parameter variables.

7.1. Simplified Design of Mounting Model. The cab is the main optimisation objective. Therefore, the parameter variable optimisation design index of the subsystem is the parameter characteristic for the stiffness and damping of the front and rear suspension. It must be considered the uneven distribution of left and right loads influenced by the driver's weight. From this, both stiffness and damping values of the front and rear suspension can be symmetrically and evenly distributed. Further, the damping can be arranged asymmetrically. Then, the cab mass is equivalent to a particle and frequency sweep signal. An input signal frequency range of 1 to $50 \mathrm{~Hz}$ is applied at the bottom of each mount, as shown in Figure 11.
Through the tested and analysed the cab mounting model in the forward jump, back jump, and vertical direction. The vibration response curves of the cab centroid in all directions are as follows:

Figure 12 shows that the frequencies with large centroid responses of the cab appear near $5.19 \mathrm{~Hz}$ and $18.59 \mathrm{~Hz}$. Further, the $Z$-direction vibration responses are large, especially in the vertical jump motion.

7.2. Parameters Optimal Design of Cab Suspension. The human body is most sensitive to changes in acceleration. The $Z$-direction vibration in the vertical direction has the greatest contribution to the cab vibration. After processing the vibration data of the cab centroid, the original timedomain signal can be converted into the cab $Z$-direction acceleration power spectrum (PSD) curve in the frequency domain environment. This is because the curve defines the peak value of the numerical square of the signal. Therefore, it is more convenient to intuitively analyse the variation of the peak value of the cab centroid acceleration vibration response with the parameters of the parts.

By taking the minimum peak value of the acceleration PSD curve of the cab centroid as the design goal. It can further take the low-order frequency of the cab and the whole vehicle as to the constraint condition. By adjusting the stiffness and damping values of cab suspension (shown in Figure 13), the best target design value is found. Based on the 
stiffness and damping data of existing models, it can finetune the adjustment range of stiffness and damping to determine the best stiffness and damping ratio gradually. The previous suspension damping and stiffness matching are illustrated in Figure 14.

As stiffness increases, the natural frequency of the mount moves backwards, and the PSD peak value of the vibration acceleration decreases slightly. At the same time, when the damping value reaches 0.4 , the PSD peak value of centroid acceleration is the lowest. This is seen when the original damping value is expanded by 0.2 variable unit value. By adjusting the stiffness and damping values of the front and rear suspension, the optimal ratio of damping and stiffness is finally determined in Table 3.

After the optimal stiffness and damping ratio of the parts is obtained, the corresponding parameters of the ratio are brought back into the whole vehicle model. Then, an experiment can be conducted to verify the accuracy of the ratio. Similarly, the sweep signal is applied to the whole vehicle tyre before and after optimisation to simulate the road signal.

Furthermore, the changes of the PSD curve of cab centroid acceleration before and after stiffness and damping optimisation are tested under the forward jump, backward jump, and vertical working conditions. The results are shown in Figure 15.

Figure 15 shows that after optimising the parameters of the cab mount, the acceleration response value of the cab centroid is reduced to an extent. This improves the driver's ride comfort. Additionally, the vibration response at the centre of the cab's mass is shown in Figure 16 when the vehicle is running at a separate speed of $35 \mathrm{~km} / \mathrm{h}$ and $105 \mathrm{~km} / \mathrm{h}$.

Optimisation results of Figure 16 show that the vertical vibration acceleration response value of the cab has reduced. Compared with the original $Z$-direction vibration acceleration response value of the cab, the optimised cab vibration response is significantly improved. This verifies the effectiveness of the model and method.

\section{Conclusion}

This paper aims to the problem of cab vibration. Firstly, the index analytic hierarchy process is proposed and used to analyse the angle of the cab vibration index. The vibration of the cab became the vibration control target. The influence trend of the parameters of the cab mounting layer on the vibration target is analysed. Then, based on the study of cab associated vibration transmission path, a virtual simulation model of vibration under multiple working conditions is established. Finally, three typical vibration responses are simulated and analysed according to the actual working conditions and the vibration behaviour of the cab. The parameters of the cab mounting layer under multiple working conditions are also studied and designed based on the model. Combined with the analysis of the experimental test results, the vibration response of the whole vehicle under the tyre rotation excitation frequency is significantly reduced. The comfort of the vehicle is improved.

\section{Data Availability}

The data used to support the findings of this study are available from the corresponding author upon request.

\section{Conflicts of Interest}

The authors declare that there are no conflicts of interest regarding the publication of this paper.

\section{Acknowledgments}

This work was supported in part by the Project of National Natural Science Foundation of China under Grant 51965013, in part by the Science and Technology Major Project of Guangxi under Grant AA18242033 and Grant AA19182004, in part by the Guangxi Natural Science Foundation Program Grant 2019JJA160025, in part by the Scientific Research and Technology Development in Liuzhou Grant 2020GAAA0404, in part by the Guangxi Science and Technology Base and Special Talents Program Grant 2018AD19077, in part by the Guangxi Key Laboratory of Manufacture System and Advanced Manufacture Technology under Grant 17-259-05-009Z, in part by the Innovation Project of Guangxi Graduate Education under Grant YCSW2020148, and in part by the Supported by GUET Excellent Graduate Thesis Program under Grant 18YJPYSS04.

\section{References}

[1] M. A. Panza, "A review of experimental techniques for NVH analysis on a commercial vehicle," Energy Procedia, vol. 82, pp. 1017-1023, 2015.

[2] W. Xiankun, Y. Xingguo, and L. Tianhua, "NVH performance prediction and optimization of a two-grade helical cylindrical gear reducer.," Journal of Ordnance Equipment Engineering, vol. 5, p. 39, 2019.

[3] L. Tiezhu, H. Rui, and H. Wei, "Torsional stiffness performance design of body-in-white based on topology optimization," Automobile Applied Technology, vol. 17, p. 66, 2019.

[4] R. V. Maikala and Y. N. Bhambhani, "Cardiovascular responses in healthy young women during exposure to whole-body vibration," International Journal of Industrial Ergonomics, vol. 38, no. 9-10, pp. 775-782, 2008.

[5] L. Sitnik, M. Magdziak-Tokłowicz, R. Wróbel, and P. Kardasz, "Vehicle vibration in human health," Journal of KONES. Powertrain and Transport, vol. 20, no. 4, pp. 411-418, 2015.

[6] M. K. Bhiwapurkar, V. H. Saran, S. P. Harsha, V. K. Goel, and M. Berg, "Effect of magnitudes and directions (mono-Axis and multi-Axis) of whole body-vibration exposures and subjects postures on the sketching performance," Proceedings of the Institution of Mechanical Engineers, Part F: Journal of Rail and Rapid Transit, vol. 225, no. 1, pp. 71-83, 2011.

[7] W. Yang, J. Chen, Z. Liu, and F. Lan, "Vibration characteristics of framed suv cab based on coupled transfer path analysis," Automotive Innovation, vol. 2, pp. 26-34, 2019.

[8] R. Wu, R. Qiongqiong, H. Lin, and L. Ying, "Piecewise polynomial fitting with trend item removal and its application in a cab vibration test," Journal of Sensors, vol. 2018, pp. 1-8, 2018.

[9] X. Liu, H. Huang, and J. Xiang, "A personalized diagnosis method to detect faults in gears using numerical simulation 
and extreme learning machine," Knowledge-Based Systems, vol. 195, Article ID 105653, 2020.

[10] X. Liu, H. Huang, and J. Xiang, "A personalized diagnosis method to detect faults in a bearing based on acceleration sensors and an FEM simulation driving support vector machine," Sensors, vol. 20, no. 2, p. 420, 2020.

[11] Y. Gao, X. Liu, and J. Xiang, "FEM simulation-based generative adversarial networks to detect bearing faults," IEEE Transactions on Industrial Informatics, vol. 16, no. 7 , pp. 4961-4971, 2020.

[12] R. He and H. Zhou, "Time-domain substructure transient vibration transfer path analysis based on time-varying frequency response functions under operational excitations," Shock and Vibration, vol. 2019, no. 3, pp. 1-16, 2019.

[13] N. Falasifah and D. Arifianto, "Vibration characteristics of a car using transfer path analysis," The Journal of the Acoustical Society of America, vol. 146, no. 4, p. 2881, 2019.

[14] J. N. Zhi, J. W. Yang, and J. Z. Dong, "Vibration performance optimization of the semi-active suspension with fuzzy control method," Advanced Materials Research, vol. 471, pp. 1123$1127,2012$.

[15] C. Guoqiang and Y. Zhifei, "Torsional vibration suppression of electric vehicle power transmission system based on parameter optimization and fuzzy control," Recent Patents on Engineering, vol. 14, 2020.

[16] Q. Wenzhong, S. Jincai, and Q. Yang, "Active control of vibration using a fuzzy control method," Journal of Sound and Vibration, vol. 275, no. 3-5, pp. 917-930, 2004.

[17] X. Liu, Y. Yuan, X. Huo, Z. S. Li, and W. Z. Li, "Model analysis method (MAM) on the effect of the second-order ionospheric delay on GPS positioning solution," Chinese Science Bulletin, vol. 55, no. 15, pp. 1529-1534, 2010.

[18] Y. Wang, Z. Wei, and J. Yang, "Feature trend extraction and adaptive density peaks search for intelligent fault diagnosis of machines," IEEE Transactions on Industrial Informatics, vol. 15, no. 1, pp. 105-115, 2019.

[19] J. Chen, Z. Deng, W. Zeng, H. Shu, and F. Rong, "Transfer path two-level modeling for cab vibration based on OPAX method," Journal of Vibration \& Shock, vol. 37, no. 3, pp. 72-78, 2018.

[20] D. Csercsik, F. Hubert, B. R. Sziklai, and L. Á. Kóczy, "Modeling transfer profits as externalities in a cooperative game-theoretic model of natural gas networks," Energy Economics, vol. 80, pp. 355-365, 2019.

[21] J. Yoshida, D. Hayashi, R. Majima, and J. Isemura, "Extracting of high contributing body vibration mode to road noise utilizing operational TPA and CAE," Transactions of Society of Automotive Engineers of Japan, vol. 50, 2019.

[22] D. Vaitkus, D. Tcherniak, and J. Brunskog, "Application of vibro-acoustic operational transfer path analysis," Applied Acoustics, vol. 154, pp. 201-212, 2019.

[23] X. Sun and J. Zhang, "Performance of earth-moving machinery cab with hydraulic mounts in low frequency," Journal of Vibration and Control, vol. 20, no. 5, pp. 724-735, 2014.

[24] R. Wu, P. Bo, S. Jiefen, L. Yang, and Y. Yi, "Study on vibration characteristics and human riding comfort of a special equipment cab,” Journal of Sensors, vol. 2018, pp. 1-8, 2018.

[25] L. L. Zhao, C. C. Zhou, and Y. W. Yu, "Hybrid modeling of seat-cab coupled system for truck," International Journal of Automotive Technology, vol. 17, no. 5, pp. 769-776, 2016.

[26] P.-A. Hansson, "Optimization of agricultural tractor cab suspension using the evolution method," Computers and Electronics in Agriculture, vol. 12, no. 1, pp. 35-49, 1995.
[27] X. U. Tie, W. Zengwei, L. Yi, C. Danhua, Q. Zhiwei, and Z. Ping, "An improved transfer path analysis method based on structural dynamic modification technique," Journal of Vibration and Shock, vol. 5, p. 32, 2019.

[28] S. K. Lee, "Identification of a vibration transmission path in a vehicle by measuring vibrational power flow," Proceedings of the Institution of Mechanical Engineers, Part D: Journal of Automobile Engineering, vol. 218, no. 2, pp. 167-175, 2004.

[29] Z. Wei and Z. Yi-Min, "Reliability analysis of random vibration transmission path systems," Mathematical Problems in Engineering, vol. 2017, pp. 1-6, 2017.

[30] W. Xu and Z. Y. Ma, "Study of the vibration transmission and path recognition of an underground powerhouse using energy finite element method," Shock and Vibration, vol. 2016, no. 1, pp. 5039578.1-5039578.9, 2016.

[31] H. Tsuji, H. Itoh, S. Mitsuta, Y. Ogasawara, K. Nishida, and N. Kanayama, "Vibration reduction of transfer feeder by dynamic absorber. dynamic absorber located on vibration transmission path," Transactions of the Japan Society of Mechanical Engineers Series C, vol. 59, no. 566, pp. 2986-2990, 1993.

[32] W. L. Song, J. W. Xiang, and Y. T. Zhong, "Mechanical parameters detection in stepped shafts using the FEM simulation based impulse excitation technique," Smart Structures and Systems, vol. 20, no. 4, pp. 473-481, 2017.

[33] G. Lepoittevin and G. Kress, "Finite element model updating of vibrating structures under free-free boundary conditions for modal damping prediction," Mechanical Systems and Signal Processing, vol. 25, no. 6, pp. 2203-2218, 2011.

[34] M. Okuma and Q. Shi, "Identification of individual rigid body modes of a system under free-free boundary condition by modal parameter estimations," Transactions of the Japan Society of Mechanical Engineers Series C, vol. 61, no. 587, pp. 2888-2894, 1995.

[35] G. Xie, D. J. Thompson, and C. J. C. Jones, "Mode count and modal density of structural systems: relationships with boundary conditions," Journal of Sound and Vibration, vol. 274, no. 3-5, pp. 621-651, 2004. 